\title{
Assessment of the some benefits of uncontrolled landfills in Georgia
}

\author{
NUGZAR BUACHIDZE ${ }^{1}$, NATELA DVALISHVILI ${ }^{2}$, EKATERINE \\ SHUBLADZE ${ }^{3}$ \\ ${ }^{1}$ Institute of Hydrometeorology of Georgian Technical \\ University, D.Aghmashenebeli ave 150g, Tbilisi 0112, \\ Georgia, ${ }^{1}$ e-mail: emc.buachidze@yahoo.com, ${ }^{2}$ e-mail: \\ n.dvalishvili@gtu.ge, ${ }^{3}$ e-mail: e.shubladze@agruni.edu.ge
}

key words: uncontrolled landfills; pollution; waste; soil

The work was supported by Shota Rustaveli National Science Foundation of Georgia (SENSFG) [grant number: FR-18718] http://rustaveli.org.ge/

\section{Study Area \& Methods}

Samples for analysis (soil) were taken from several sites of the landfill territory ( $0-25 \mathrm{~cm}$. depth from surface).. After complete drying, we prepared samples for final analysis. To determine the components, special ISO spectrophotometric methods were used $[1,2]$.

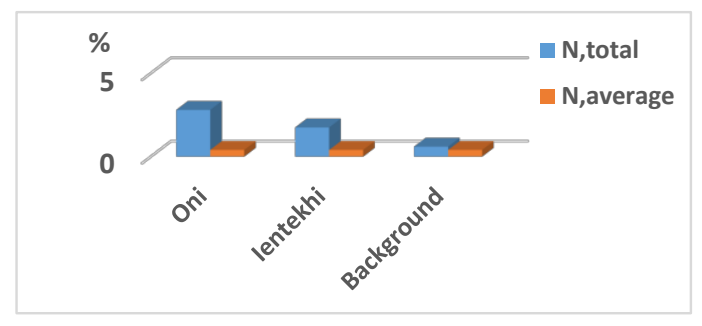

Total Nitrogen concentration in the soil samples collected in Racha-Kvemo Svaneti Region

\section{Results \& Discussions}

As we can see, most of the soils of uncontrolled landfills in these regions obviously contain high level of nitrogen, whose concentrations are quite high compared to background points as well as average soil values, which leads to the conclusion that these types of landfill soils can be used (after some particular technological recycling) as fertilizer for enriching any other poor soil.

[1] AS. Erses, MA Fazal, Onaya TT, Craig WH. Determination of solid waste sorption capacity for selected heavy metals in landfills. J Hazard Mater (2005); [2] Elina Bakradze., Yuri Vodyanitski., Tengiz Urushadze., Zaur Chankseliani., Marine Arabidze. About rationing of the heavy metals in Soils of Georgia. J. Annal of Agrarian Science, vol.16,№1 (2018). 